\title{
Holocene chronostratigraphy and paleoclimate implications of dune fields across southern Utah
}

Harriet Cornachione, Tammy Rittenour, Michelle Nelson USU Geology Department \& USU Luminescence Laboratory

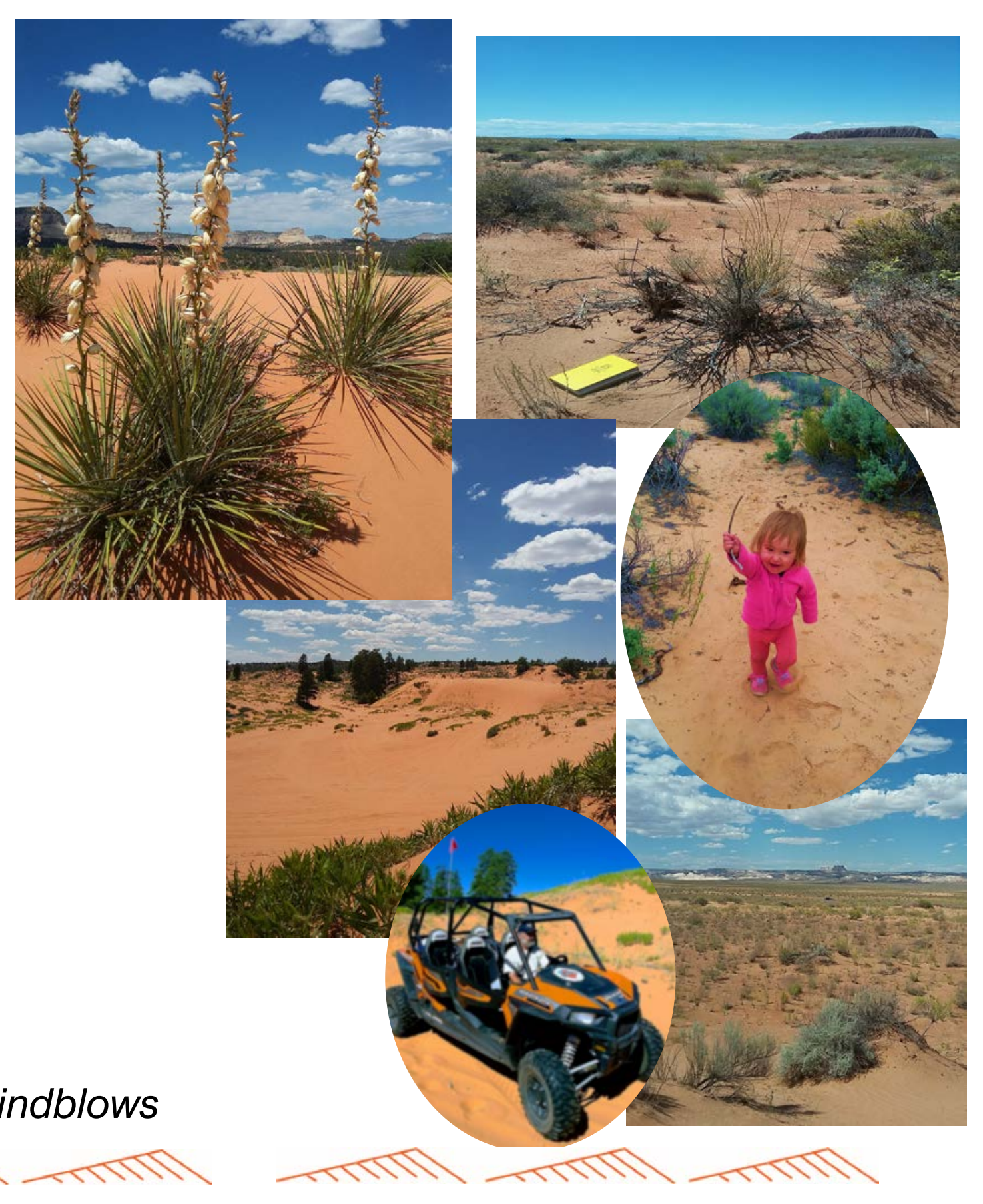

\#dunetrekking \#droughtstudy \#redsandsoftime \#wherethewindblows

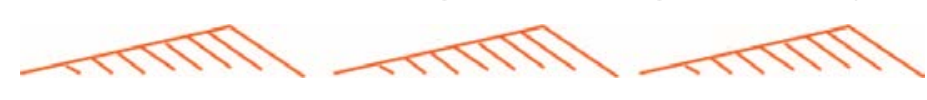




\section{PROJECT INTRODUCTION}

- Recent $\left(20^{\text {th }}-\right.$ early $21^{\text {st }}$ century) droughts - annual to multi-annual

- Medieval (900 - 1100 A.D.) droughts - decadal to multi-decadal and centennial

- Drought forecasts (late $21^{\text {st }}$ century) likely similar or greater duration than medieval droughts

Understanding past climates can inform us about future climate change and aid us in developing adaptive strategies for changing conditions.

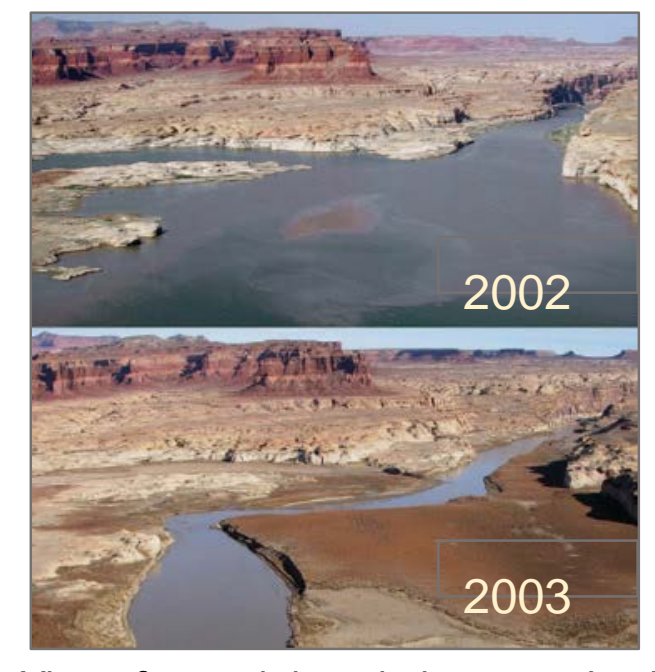

View of annual drought impact at Lee's Ferry, courtesy US Geological Survey.
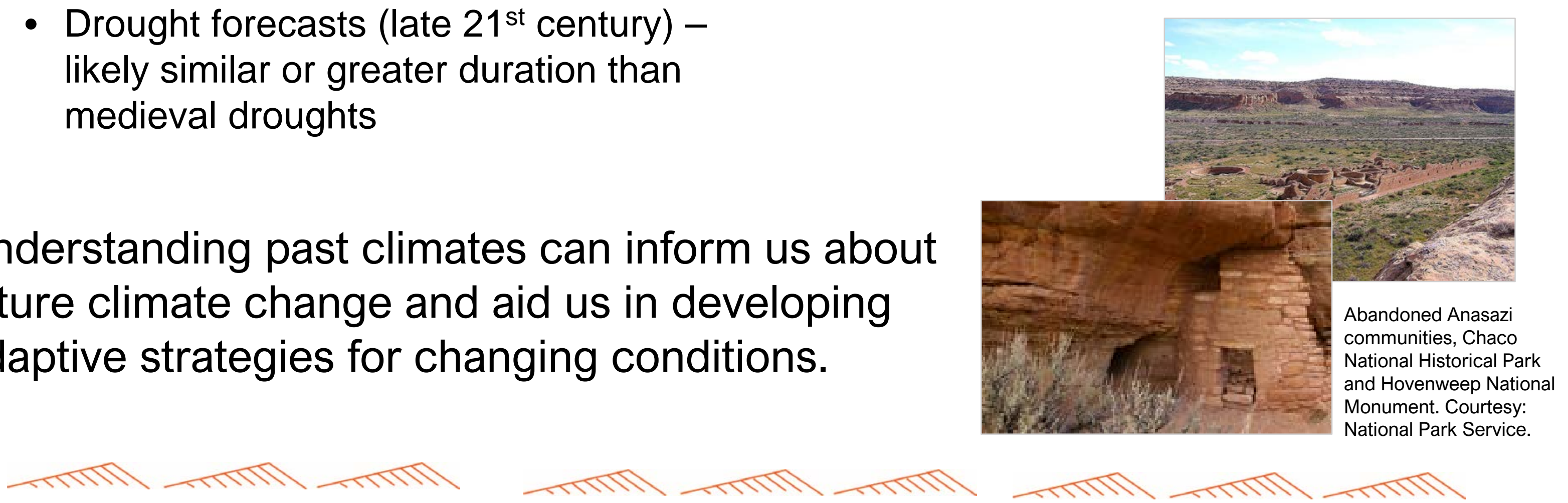


\section{PROJECT LOCATION}

\section{Southern Utah}

- is readily accessible

- fills a data gap

- offers a regional record
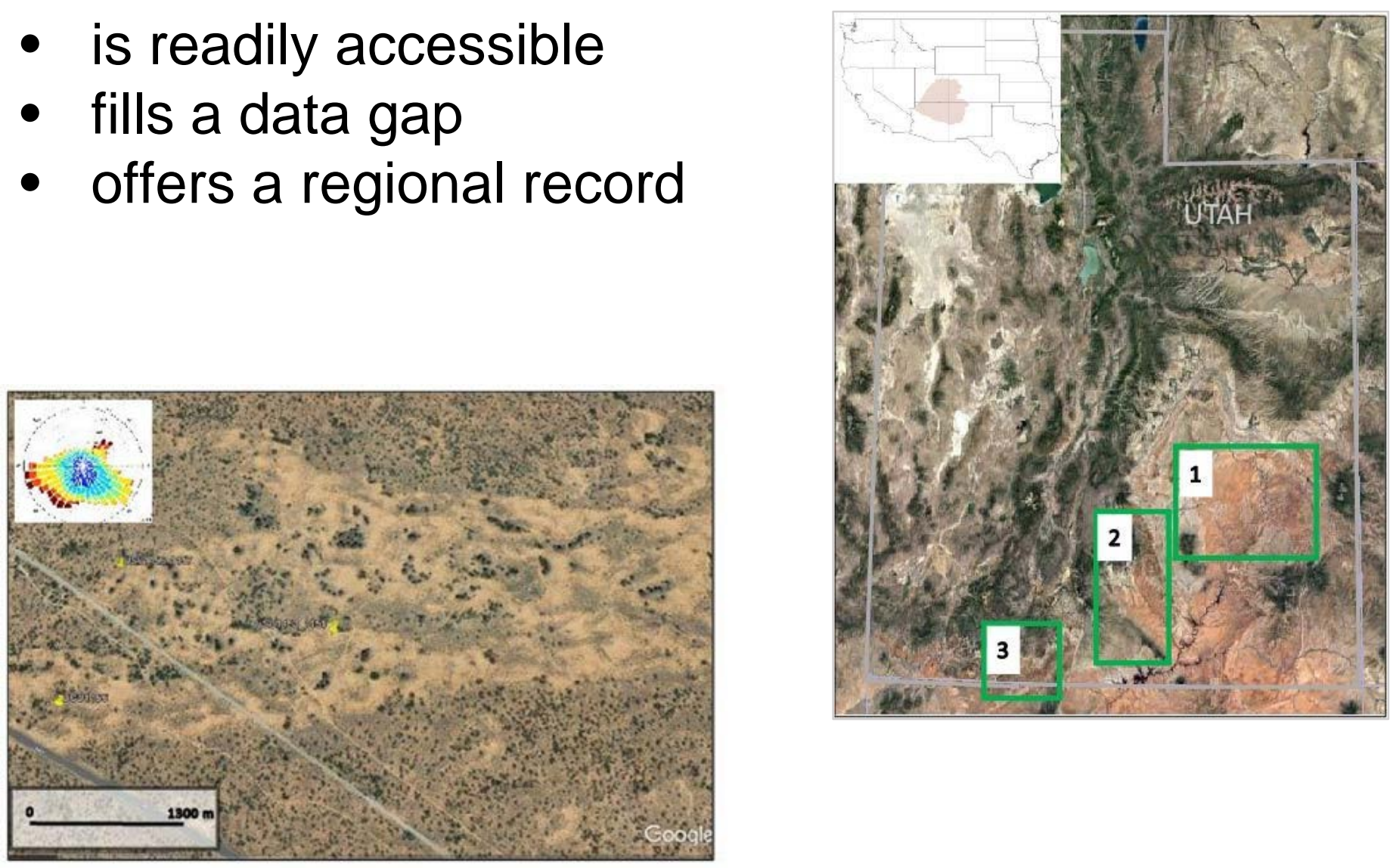

Area 3. Kanab dune field - stabilized (vegetated) sand sheet, partially stabilized, long parabolic dunes and blowout features.

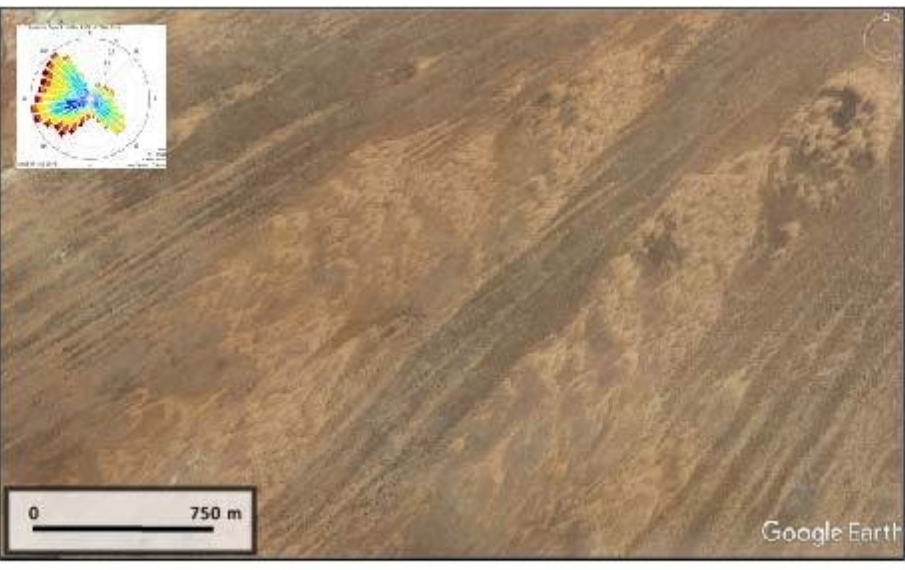

Area 1. San Rafael Desert dune field stable relict limbs, hairpin parabolic, active parabolic dunes.

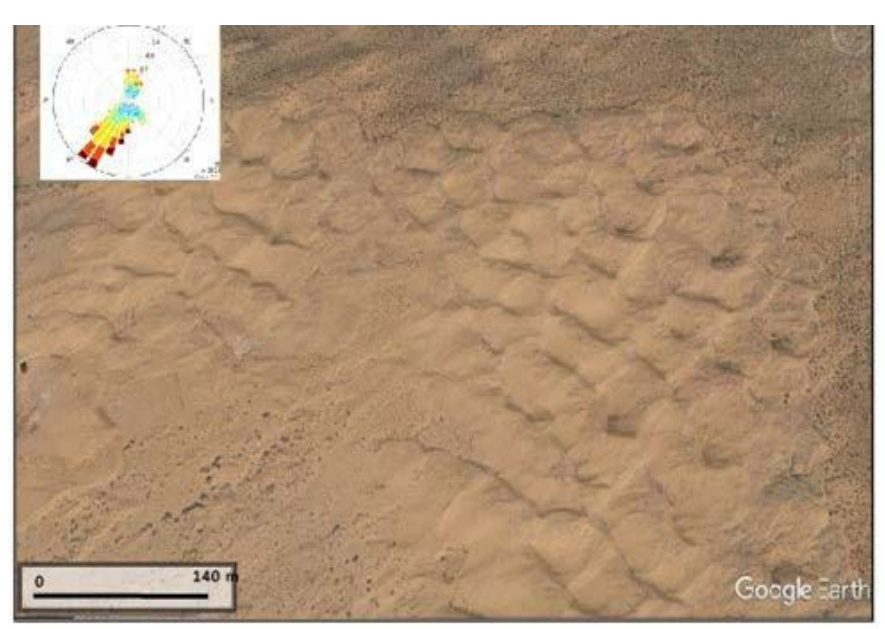

Area 2. Escalante Desert dune field - active barchan dunes, transverse ridges, overlie stabilized (vegetated) sand sheet. 


\section{RESEARCH QUESTIONS}

- When have southern Utah dunefields been active during the Holocene age (past 12,0000 years)?

- Are multiple dunefields active at the same time?

- Do periods of dunefield activity correlate with other drought proxy data in the Colorado Plateau?

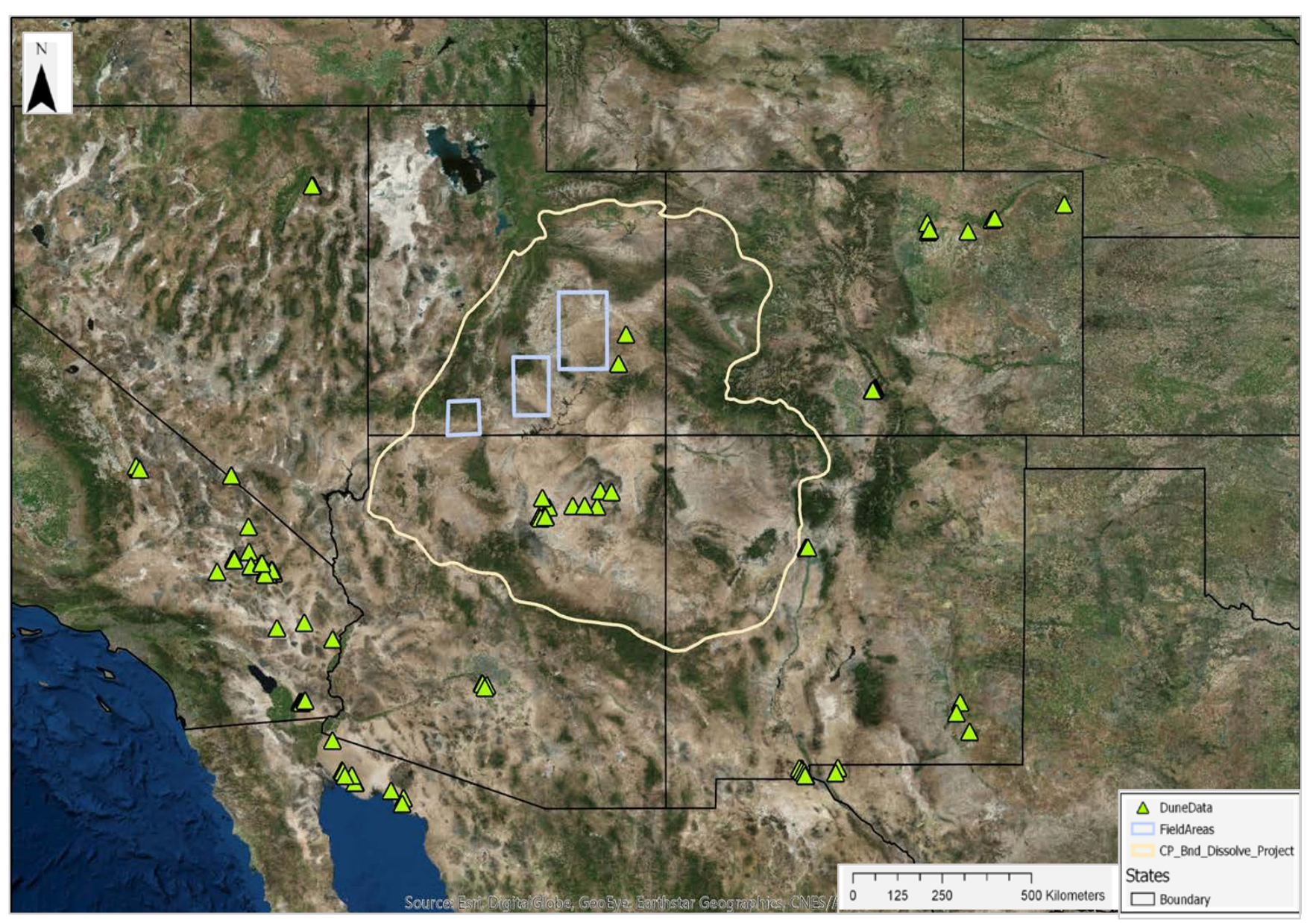

Hypothesis:

Dune activity occurring concurrently across southern Utah suggests regional drought (decadal or longer) occurred at that / those times. 


\section{APPROACH \& METHODS}

- Map geomorphic units in dunefields

- Hand-auger coreholes to sample and characterize dune sediments
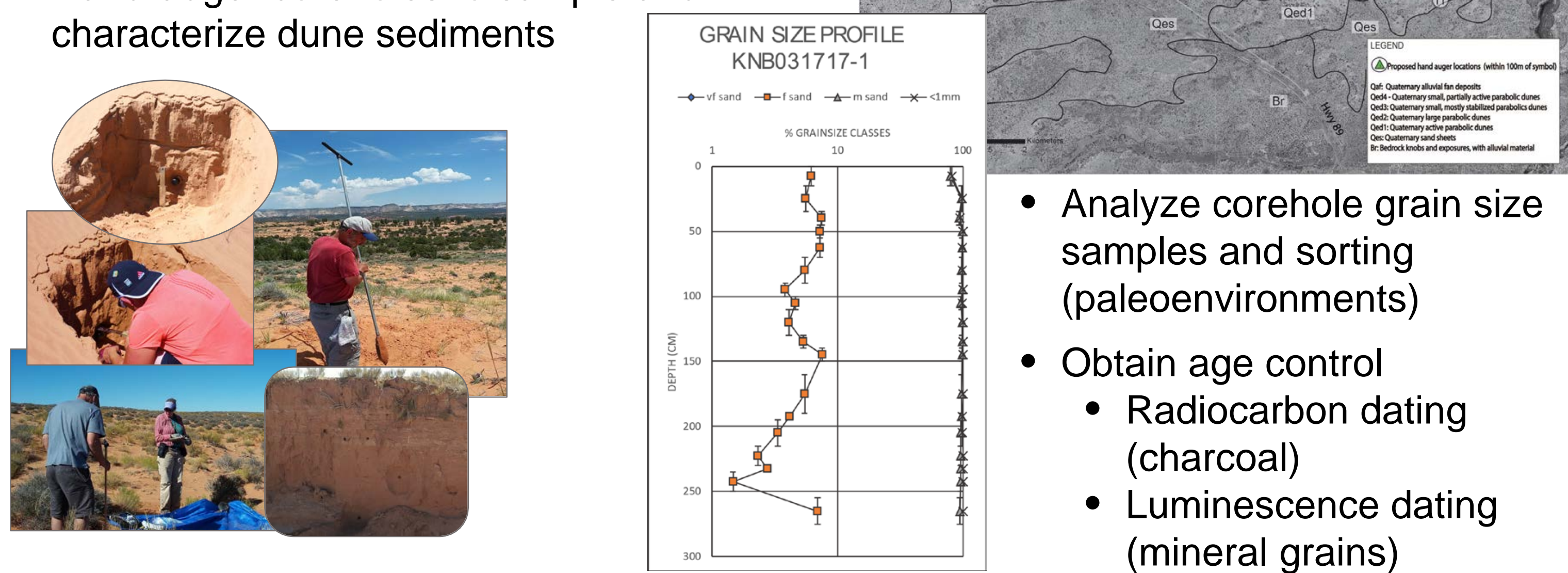

- Analyze corehole grain size samples and sorting (paleoenvironments)

- Obtain age control

- Radiocarbon dating (charcoal)

- Luminescence dating (mineral grains) 


\section{PRELIMINARY AGE RESULTS}

Hypothesis:

Concurrent dune activity across southern Utah suggests regional drought (decadal or longer) occurred at that / those times.

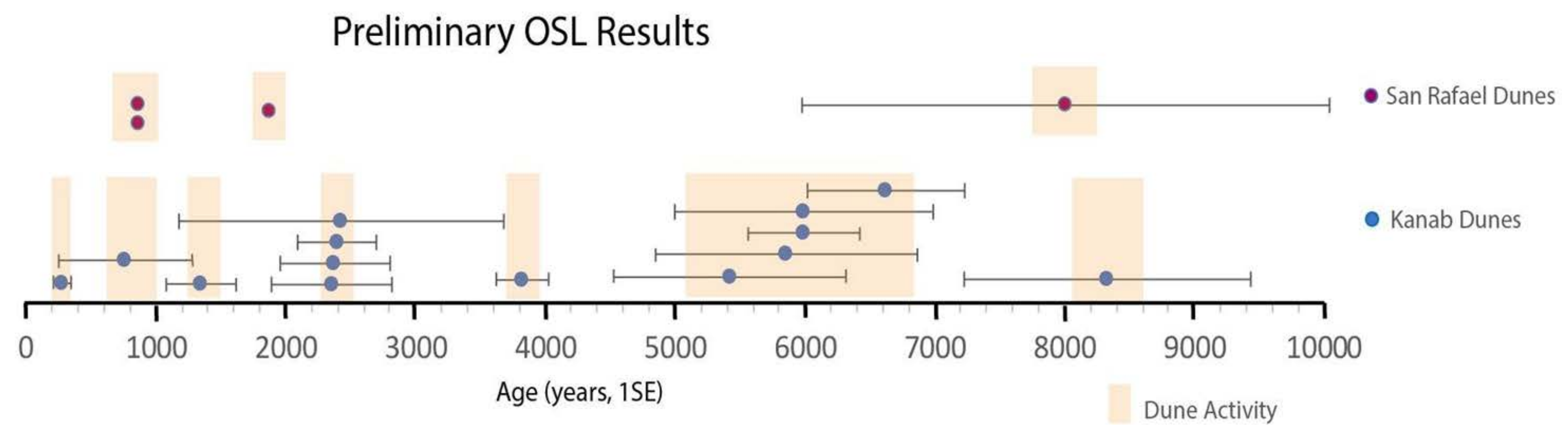




\section{FUTURE WORK}

- Collect dune samples - San Rafael and Escalante dunefields

- Obtain age records (luminescence and radiocarbon dating)

- Develop stratigraphy / paleoenvironmental chronologies

- Comparison with other climate proxy records for Colorado Plateau

Example of other climate data

- Colorado Plateau Region

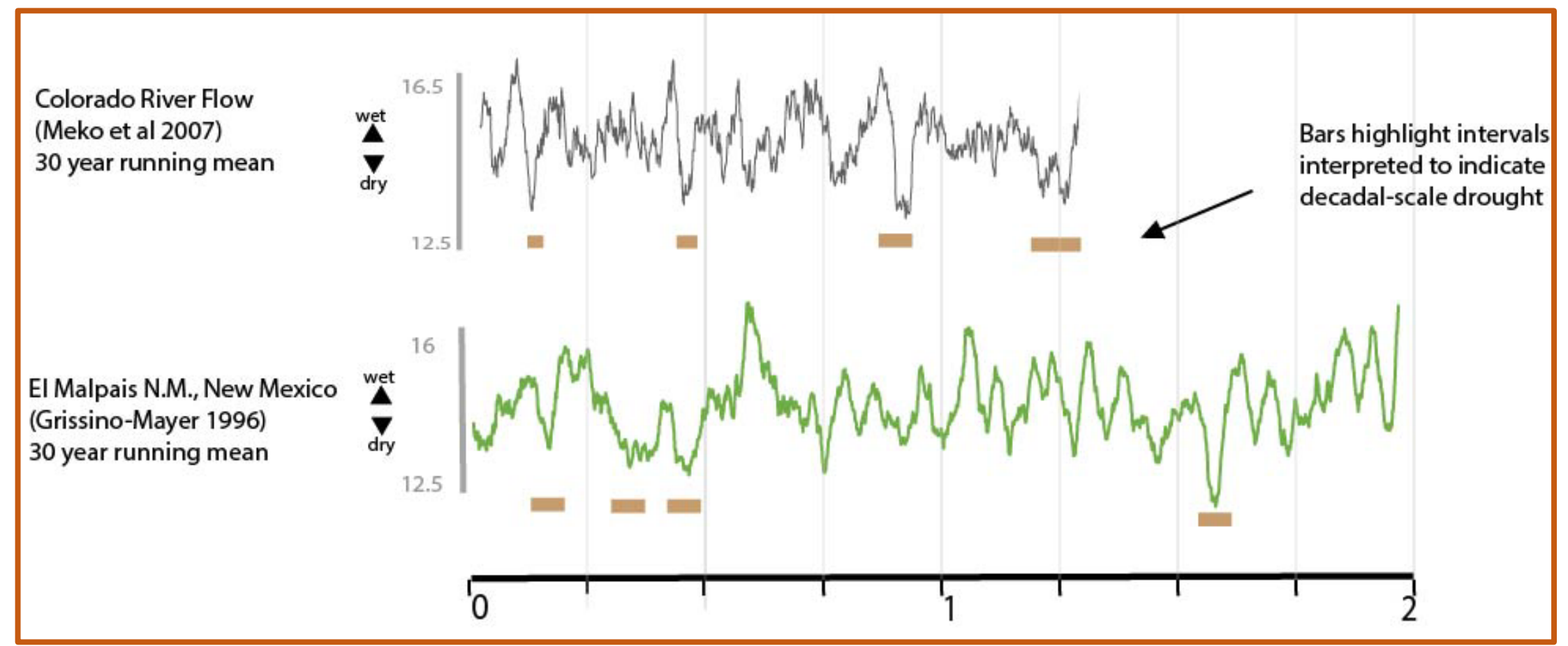




\section{GRATITUDE}

My deepest gratitude to the following people, whose guidance and support made this work possible.

- Dr. Tammy Rittenour, USU Geology Department and Director, USU Luminescence Laboratory

- Carlie Ideker and Michelle Nelson, USU Luminescence Laboratory

- Fellow graduate students, especially Alexander Short, Kerry Riley and Robert McDermott for generously sharing their knowledge, wisdom and time

- Michael Cornachione and Jade Cornachione, my field assistants

- Andrew Perkins, grain size analyses and tech support

\section{SUPPORT}

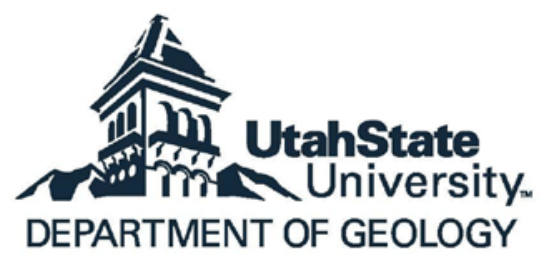

Funding for this project is provided by the following organizations

- National Science Foundation

- Geological Society of America

- Earthscope

- Association of Women Geoscientists

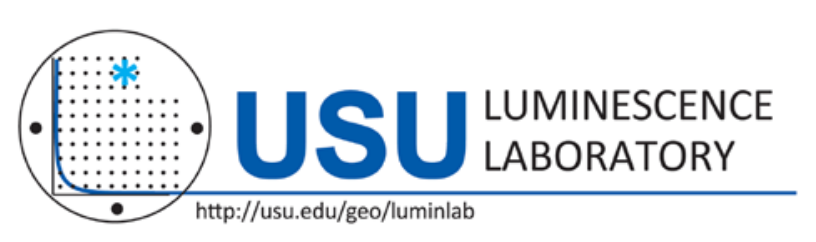
DEPARTMENT OF GEOLOGY

- Colorado Scientific Society

- USU Department of Geology
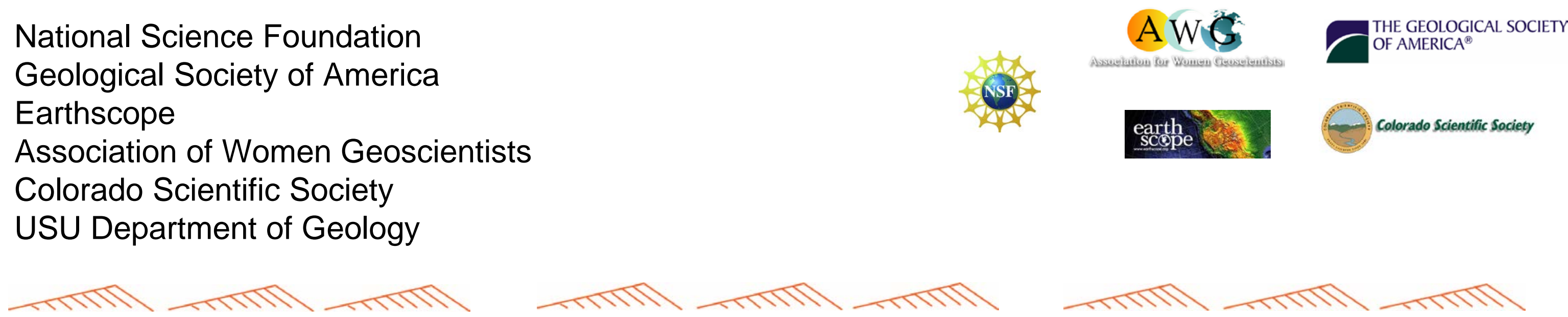